\title{
B. Ann Tlusty, The Martial Ethic in Early Modern Germany. Civic Duty and the Right of Arms
}

Basingstoke: Palgrave Macmillan (Early Modern History. Society and Culture), 2011, 371 p., $60 €$

Jean-Dominique Delle Luche

\section{OpenEdition}

\section{Journals}

Édition électronique

URL : http://journals.openedition.org/ifha/7723

DOI : $10.4000 /$ ifha. 7723

ISSN : 2198-8943

\section{Éditeur}

IFRA - Institut franco-allemand (sciences historiques et sociales)

\section{Référence électronique}

Jean-Dominique Delle Luche, «B. Ann Tlusty, The Martial Ethic in Early Modern Germany. Civic Duty and the Right of Arms », Revue de l'IFHA [En ligne], Date de recension, mis en ligne le 15 décembre 2013, consulté le 22 septembre 2020. URL : http://journals.openedition.org/ifha/7723 ; DOI : https://doi.org/ 10.4000/ifha. 7723

Ce document a été généré automatiquement le 22 septembre 2020.

(CIFHA 


\section{B. Ann Tlusty, The Martial Ethic in Early Modern Germany. Civic Duty and the Right of Arms}

Basingstoke: Palgrave Macmillan (Early Modern History. Society and Culture), 2011, 371 p., $60 €$

Jean-Dominique Delle Luche

L'ouvrage de B. Ann Tlusty, professeur à l'Université Bucknell (Pennsylvanie), marque l'aboutissement de plusieurs années de recherches en histoire sociale de l'Allemagne de la première modernité, en particulier sur le comportement masculin dans l'espace public. En témoignent, dans le présent ouvrage, le recours fréquent à des documents judiciaires d'archives du sud de l'Allemagne (Augsbourg au premier chef) ainsi que 1 'utilisation des concepts de masculinité et de comportement " genré ».

La période étudiée, le tournant du XVIIe siècle et notamment la Guerre de Trente Ans, est l'occasion de réévaluer les théories de la «révolution militaire» en soulignant la capacité des populations urbaines à assurer la défense de leur propre ville. Cependant, au-delà de la simple étude du fait martial en ville, c'est une époque précise de la civilisation urbaine allemande, «l'âge de l'épée », qu'essaie de reconstituer l'auteur.

Appuyé sur un appareil de notes rigoureux, l'ouvrage est composé de dix chapitres, sous forme de synthèses ou d'études de cas. Le système de la garde de nuit, les duels, les pratiques martiales ludiques du tir ou de l'escrime y sont remarquablement présentées. On appréciera également deux études en particulier, la première relatant un conflit entre les habitants et la garnison suédoise de Nördlingen, au moment où deux autorités, l'une militaire et l'autre civile, prétendent chacune assurer l'ordre; la seconde analyse les tensions autour de la réforme du calendrier à Augsbourg, et la méfiance réciproque entre le conseil et une partie de la population protestante qui craint une seconde nuit de la Saint-Barthélemy et privilégie l'autodéfense.

Par cette organisation dynamique entre généralités et études de cas, l'ouvrage permet de dépasser le concept théorique de Wehrverfassung (organisation militaire) urbaine. Il propose un panorama de la culture des armes en ville qui ne saurait se résumer à la 
seule chose militaire, mais adopte le cadre plus pertinent du quotidien martial vécu par les individus et autorisé par la collectivité. Droit et pratiques sont différenciés non seulement selon le sexe, mais aussi selon la catégorie sociale: paysans, artisans, étudiants, membres du clergé, Juifs, et soldats prétendent à un même comportement martial ou viril, même lorsque les autorités inclinent à le restreindre ou à l'interdire. Des tableaux statistiques sur les arsenaux domestiques et sur les actes criminels constituent un élément supplémentaire dans l'analyse de la répartition sociale des armes en ville. La lecture est de plus agrémentée par des descriptions vivantes du quotidien : on remarquera en particulier de belles pages sur la révolution que constitue l'arrivée de la poudre dans le paysage sonore urbain.

Dans la colère, l'alarme ou la joie, le bourgeois recourt aux armes. Mais, selon qu'il trouble en cela la paix ou la défend au contraire, et s'il respecte ou non un code d'honneur, ce recours peut être légitimé ou condamné. Le bourgeois, qui a le droit (sinon le devoir) de recourir à la violence pour faire respecter l'ordre et la paix le cas échéant, doit insister sur des éléments codifiés attestant ses bonnes intentions lorsqu'il rend compte de son action.

On peut néanmoins regretter que les exemples de l'auteur soient trop concentrés sur le cas des villes libres d'Empire (il est vrai majoritaires dans la région, avec des fonds d'archives assez riches) et non sur les villes territoriales. L'excursus sur le droit des armes dans le Wurtemberg est restreint à l'échelle de la principauté; une étude à l'échelle des villes individuelles aurait permis une réflexion complémentaire et plus large sur les rapports possibles entre le statut politique des autorités urbaines, la pratique législative, le quotidien des habitants et la production de documents judiciaires. Au-delà de ce regret relatif, le livre de B. Ann Tlusty reste un ouvrage de première qualité pour l'histoire urbaine de la première modernité, et une clé de comparaison bienvenue pour les historiens des périodes proches.

\section{INDEX}

Index chronologique : Frühe Neuzeit

Thèmes : Militärgeschichte, Sozialgeschichte, Regionale Geschichte/ Stadtgeschichte

\section{AUTEUR}

JEAN-DOMINIQUE DELLE LUCHE

EHESS 